\title{
Combined antegrade femur lengthening and distal deformity correction: a case series
}

Achraf Jardaly ${ }^{1,2}$ and Shawn R. Gilbert ${ }^{2,3^{*}}$ (i)

\begin{abstract}
Background: Leg length discrepancy is often associated with distal femur angular deformities such as valgus or flexion. This study aims to report a new technique for simultaneous limb lengthening and acute distal femoral angular correction.
\end{abstract}

Methods: A retrospective chart review of patients undergoing a single procedure was conducted. Patients included had a single operation where they underwent distal femur osteotomy stabilized with a plate followed by antegrade nailing with a magnetically controlled intramedullary lengthening nail (PRECICE, Ellipse Technologies, Inc., Irvine, CA, USA) using a trochanteric entry.

Results: Seven femurs from 7 patients were included. The average age at operation was 13.6 years, and the leg length difference was $51 \mathrm{~mm}$ (range 30-105 mm). Associated deformities were valgus (4), knee flexion contracture (2), and both valgus and flexion contracture (1). Lengthening achieved was $43 \mathrm{~mm}(P=0.0036)$, with a consolidation index of 27 days $/ \mathrm{cm}$ and reliability of $0.87(6 / 7)$. The 5 patients with angulation had an improvement of valgus from 12 to $4^{\circ}(P=0.006)$ and of the mechanical axis deviation from 34 to $3 \mathrm{~mm}(P=0.0001)$. The range of motion also improved in the 3 patients with contractures. Preoperative gait disturbance, hip and knee pain, and functional scoliosis resolved after the limb deformities were corrected.

Conclusion: Combining a magnetic internal lengthening nail with a second distal osteotomy stabilized with a plate can successfully correct limb length and distal femur deformity acutely without altering the expected result of each procedure.

Keywords: Leg length discrepancy, Combined femoral deformities, Limb lengthening, PRECICE nail, Magnetic intramedullary nailing, Two-level osteotomy

\footnotetext{
* Correspondence: srgilbert@uabmc.edu

${ }^{2}$ Department of Orthopedic Surgery, University of Alabama at Birmingham, Birmingham, AL, USA

${ }^{3}$ Department of Pediatric Orthopaedics, ACC Suite 316, Children's Hospital of Alabama, 1600 7th Avenue South, Birmingham, AL 35233, USA

Full list of author information is available at the end of the article
}

(c) The Author(s). 2021 Open Access This article is licensed under a Creative Commons Attribution 4.0 International License, which permits use, sharing, adaptation, distribution and reproduction in any medium or format, as long as you give appropriate credit to the original author(s) and the source, provide a link to the Creative Commons licence, and indicate if changes were made. The images or other third party material in this article are included in the article's Creative Commons licence, unless indicated otherwise in a credit line to the material. If material is not included in the article's Creative Commons licence and your intended use is not permitted by statutory regulation or exceeds the permitted use, you will need to obtain permission directly from the copyright holder. To view a copy of this licence, visit http://creativecommons.org/licenses/by/4.0/ The Creative Commons Public Domain Dedication waiver (http://creativecommons.org/publicdomain/zero/1.0/) applies to the data made available in this article, unless otherwise stated in a credit line to the data. 


\section{Background}

Abnormalities in the femur and tibia are the leading cause of leg length difference (LLD). These abnormalities commonly stem from congenital, infectious, or traumatic conditions [1]. While a variety of conservative and operative options exists, limb lengthening procedures are increasingly preferred due to technical advances and patient preference [2]. These procedures have drastically changed with the advent of intramedullary lengthening rods. Nonetheless, osteogenesis by distraction as described by Ilizarov is still how lengthening is achieved [3]. Internal lengthening nails (ILN) have the advantage of eliminating the need for external fixators and their associated complications [4-6]. Among the lengthening devices, magnetic intramedullary nails offer the most accurate distraction and precise lengthening [1, 2, 4, 6-11].

Magnetic ILN have advanced limb reconstruction, greatly achieving higher patient satisfaction, more reliable outcomes, and fewer complications than other lengthening methods $[2,4,12,13]$. However, patients with combined deformities still remain a challenging group, and they require multiple operations. Short limbs often also have angular deformities [14]. Deformities in the distal femur can exacerbate patients' LLD and could need to be surgically addressed. As such, additional procedures might be needed over what is already a technically challenging operation with a long healing process. Simultaneous lengthening and significant deformity correction are considered a contraindication to magnetic ILN by some authors [4].

Few reports exist on concomitant procedures to address combined deformities. They demonstrate adequate correction of angular deformities and LLD using one operation, but an external fixator is typically used [14-16]. Most commonly, retrograde nailing with blocking screws is used for distal femur deformities [14, 17]. To avoid complications associated with this technique, here, we report our experience with a less common approach in the correction of different distal femur angular deformities accompanying LLD: antegrade nailing and the use of a distal femoral osteotomy (DFO) stabilized with a plate [18].

This manuscript aims to advance clinical outcomes and can be considered to fit in the framework of translational orthopedics. This is in concordance with an increasing number of publications attempting to advance orthopedic practice [19].

\section{Methods}

This is a retrospective review conducted at a single institution following Institutional Review Board approval (University of Alabama at Birmingham IRB-300004224 on March 2020). Patients undergoing concurrent femur lengthening and distal femoral osteotomy were included. Charts were reviewed for patient demographics, etiologies of the deformities, indications for surgery, operative details, and clinical findings and complications documented in clinical visits. The Paley classification of difficulties during lengthening procedures (problems, obstacles, and true complications) was used [20]. Problems are difficulties that resolve without operative intervention, obstacles require reoperation, and true complications are intraoperative injuries as well as problems that persist after the treatment ends. The reliability of lengthening was determined as defined by Schiedel et al: as the ratio of the number of

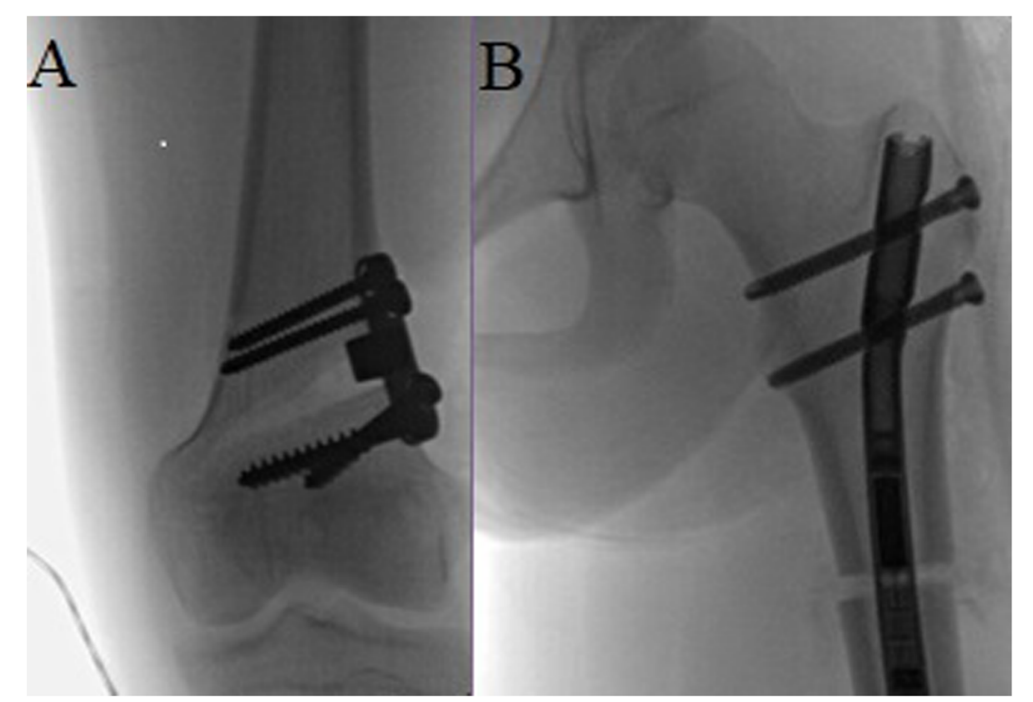

Fig. 1 Intraoperative fluoroscopy demonstrates a stable distal femur osteotomy and $\mathbf{b}$ functioning lengthening nail with adequate distraction 
successful treatments achieving bony consolidation to the number of total implants [7]. Pre- and postoperative radiographs were used to determine the leg length difference, the valgus deformity, the mechanical axis deviation (MAD), the lateral distal femoral angle (LDFA), and the medial proximal tibial angle (MPTA). Student $t$ tests were used to compare measurements before and after the surgery, with the threshold of statistical significance set at a two-tailed $P$ value of 0.05 [21].

\section{Surgical procedure}

The senior author performed all surgeries at a single institution. The operation was started by performing the DFO. A lateral approach was used, and with the assistance of a guide wire, a wedge osteotomy was performed. The osteotomy was then stabilized with a plate.

An antergrade, magnetically controlled intramedullary lengthening nail (PRECICE, Ellipse Technologies, Inc., Irvine, CA, USA) was inserted in the established technique using a trochanteric entry point [22]. Fluoroscopy confirmed adequate placement of the hardware and functioning of the nail intraoperatively (Fig. 1). The nail was tested intraoperatively for proper lengthening using an external remote control magnet. Patients were discharged within 1 to 3 days of the procedure. Lengthening was started on postop days 4 to 8 , at a rate of $1 \mathrm{~mm} /$ day over 3 sessions. Follow-up visits were performed at 1 - to 2-week intervals to monitor the range of motion, and lengthening and alignment were verified by radiographs (Fig. 2).

\section{Results}

Since the introduction of the PRECICE nail in December 2011, 32 patients underwent a femur lengthening procedure at our institution, 20 of which utilized the magnetic ILN. Seven patients (7 femurs) underwent concurrent lengthening with a magnetic ILN and DFO. The average age at operation was 13.6 years (Table 1). DFO was performed to correct excessive valgus (4 patients), flexion deformity (2), or both deformities (1).

All patients had LLD $\geq 30 \mathrm{~mm}$ and were symptomatic (Table 2). By the final follow-up visit, these symptoms had resolved except for one patient complaining of mild knee pain. Six patients healed without complications, while 1 patient experienced osteomyelitis and fixation failure 15 days postop. Of note, she had previous lengthening and prior intramedullary nail placement with surrounding sclerosis along a path other than the desired one for the lengthening. This made creating and reaming a new path for the magnetic ILN very challenging. She underwent debridement and nail replacement. Therefore, we had 1 obstacle, and the reliability was $0.86(6 / 7)$.

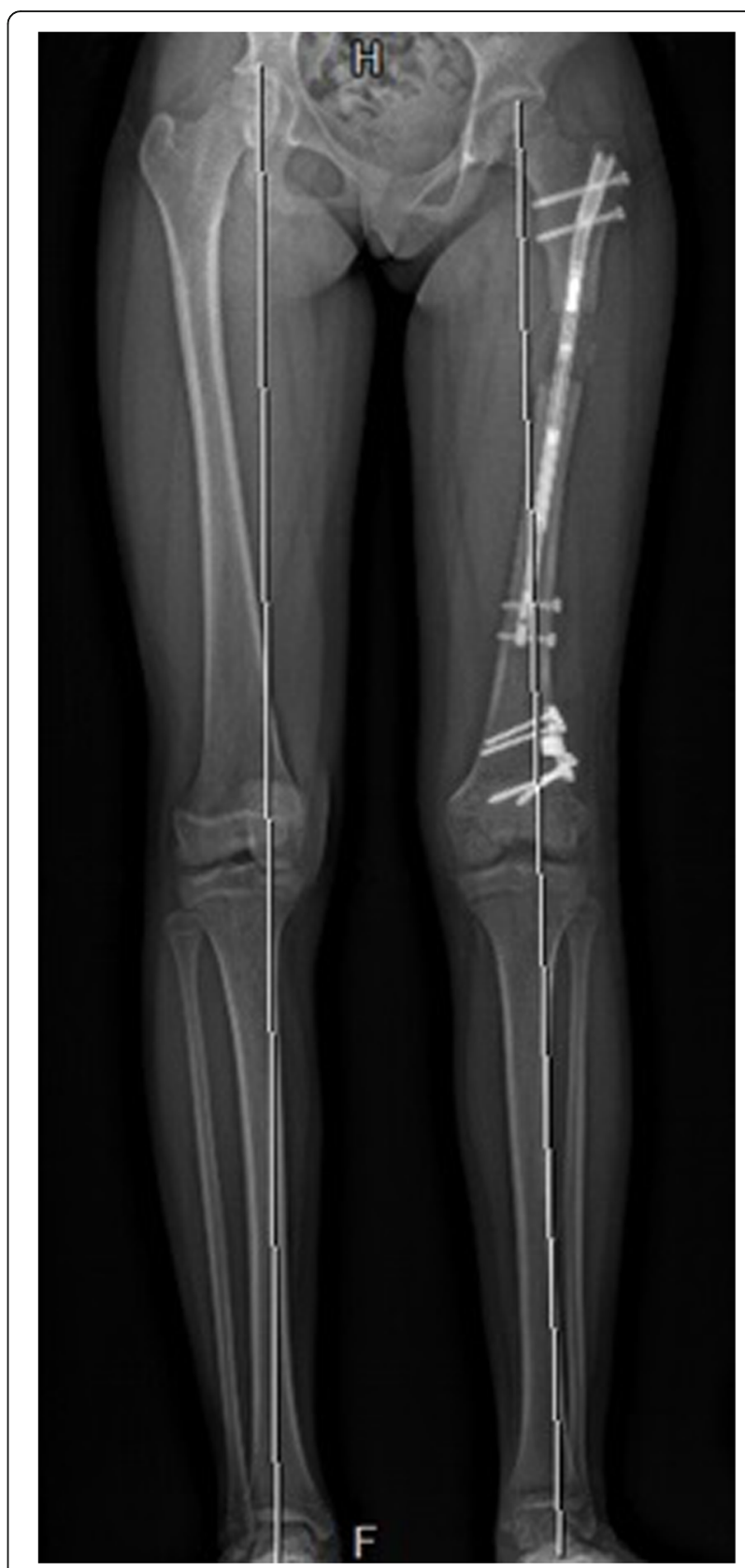

Fig. 2 X-ray at a follow-up visit demonstrates interval lengthening and good alignment of the weight-bearing axis

The average lengthening achieved was $43 \mathrm{~mm}$ (Table 3). No premature or delayed consolidation was observed, and the consolidation index was 27 days $/ \mathrm{cm}$ on average. For the 5 patients with valgus, the average angulation was $12^{\circ}$, which was mostly due to femoral deformity (Table 3 ). Valgus and mechanical axis deviation were corrected by $8^{\circ}$ $(P=0.006)$ and $31 \mathrm{~mm}(P=0.0001)$, respectively.

Three patients initially had knee flexion deformity. They improved clinically and reached their target range 
Table 1 Patient demographics and operative details

\begin{tabular}{|c|c|}
\hline Variable & Value \\
\hline Age* $^{*}$ years & $13.6(10.75-16.2)$ \\
\hline \multicolumn{2}{|l|}{ Sex, number } \\
\hline Male & 2 \\
\hline Female & 5 \\
\hline Weight*, kg & $58.1(43.4-73.2)$ \\
\hline \multicolumn{2}{|l|}{ Laterality, number } \\
\hline Right & 4 \\
\hline Left & 3 \\
\hline \multicolumn{2}{|l|}{ Previous lengthening operations, number } \\
\hline 0 & 2 \\
\hline 1 & 3 \\
\hline 2 or more & 2 \\
\hline \multicolumn{2}{|l|}{ Cause, number } \\
\hline Congenital femoral deficiency & 2 \\
\hline Meningococcemia & 2 \\
\hline Russell-Silver syndrome & 1 \\
\hline Ollier's syndrome & 1 \\
\hline Idiopathic & 1 \\
\hline \multicolumn{2}{|l|}{ Associated deformity, number } \\
\hline Valgus & 4 \\
\hline Knee flexion contracture & 2 \\
\hline Both valgus and knee flexion contracture & 1 \\
\hline Blood loss*, mL & $246(50-500)$ \\
\hline Surgery time*, h:min & $3: 30(2: 16-5: 02)$ \\
\hline Follow-up duration*, months & $22(8-49)$ \\
\hline
\end{tabular}

${ }^{*}$ Each value is expressed as the mean, with the range in parenthesis

of motion (Table 4). The four remaining patients regained their full knee range of motion in less than 4 months following the index procedure.

\section{Discussion}

In this paper, we report our experience in combining antegrade nailing and a plate-stabilized DFO to target LLD and valgus and/or flexion contractures in seven patients. Our patients achieved their planned lengthening and had a clinically significant correction of their other deformities (Fig. 3). Preoperative gait disturbance, hip and knee pain, and functional scoliosis resolved in

Table 2 Symptoms of patients before and after surgery

\begin{tabular}{lll}
\hline & $\begin{array}{l}\text { Pre-surgery, number } \\
\text { (\%) }\end{array}$ & $\begin{array}{l}\text { Post-surgery, number } \\
\text { (\%) }\end{array}$ \\
\hline Gait abnormality & $4(57 \%)$ & 0 \\
Knee pain & $3(43 \%)$ & $1(14 \%)$ \\
Back pain & $2(28 \%)$ & 0 \\
Functional scoliosis & $2(28 \%)$ & 0 \\
\hline
\end{tabular}

Table 3 Length and angular deformities

\begin{tabular}{lllllll}
\hline & \multicolumn{2}{c}{ Pre-surgery } & & \multicolumn{2}{c}{ Post-surgery } & \multirow{2}{*}{ P value } \\
\cline { 2 - 3 } & Mean \pm SD & Range & & Mean \pm SD & Range & \\
\hline LLD $(n=7), m m$ & $51 \pm 26$ & $30-105$ & & $8 \pm 8$ & $1-23$ & 0.0036 \\
Angulation $(n=5)$ & & & & & \\
Valgus, degrees & $12 \pm 4$ & $7-16$ & $4 \pm 2$ & $2-7$ & 0.006 \\
MAD, mm & $34 \pm 8$ & $27-45$ & $3 \pm 5$ & $0-11$ & 0.0001 \\
LDFA, degrees & $82 \pm 8$ & $72-94$ & $87 \pm 4$ & $80-90$ & 0.28 \\
MPTA, degrees & $92 \pm 7$ & $82-99$ & $90 \pm 2$ & $87-91$ & 0.60 \\
\hline
\end{tabular}

LDFA lateral distal femoral angle, $L L D$ limb length discrepancy, $M A D$ mechanical axis deviation, MPTA medial proximal tibial angle, $S D$ standard deviation

all but one patient after the limb deformities were corrected. The one patient with knee pain postoperatively reported great improvement in the pain compared to before the surgery. No cases of avascular necrosis occurred, confirming previous findings regarding the safety of femoral lengthening via a trochanteric entry in children [23].

The consolidation index of our patients was 27 days/ $\mathrm{cm}$, comparable with the values between 31.6 and 33.6 days $/ \mathrm{cm}$ reported in the literature. This indicates that bone healing was not affected and that consolidation can be expected to occur as normally anticipated without delay. Similarly, the reliability of our lengthening was 0.86 . Magnetic ILN used in patients with LLD typically have a reliability between 0.78 and 0.85 due to the challenges posed by this patient population $[7,8,24-26]$. Furthermore, deformity correction in our patients was successful in terms of desired length and angulation correction. After the surgery and at a lengthening rate of 1 $\mathrm{mm}$ /day, the mean LLD was only $8 \mathrm{~mm}$, with an average correction of $43 \mathrm{~mm}$. This correction is in line with the usual lengthening achieved using the PRECICE nail, which has commonly reported lengthening averages between 35 and $44 \mathrm{~mm}[7-9,18]$. Achieved MAD and LDFA correction in patients with valgus were $18.3 \mathrm{~mm}$ and $5.8^{\circ}$, respectively, in a prior study using an external fixator in conjunction with an ILN to achieve simultaneous femoral lengthening and deformity correction [14]. Our results were similar, with MAD correction of 31 $\mathrm{mm}$ and LDFA correction of $5^{\circ}$. Our favorable outcomes suggest that a DFO does not compromise the lengthening and healing processes as indicated by the reliability and consolidation index, respectively. Though this results in a longer operation, the advantages of a combined procedure offset the increased surgery time. Such advantages include avoiding a 2 nd procedure with general anesthesia and subsequent recovery time and postoperative pain, reducing cost, and decreasing hospitalization [15]. As a result, the simultaneous correction of multiple femoral deformities is expected to be 
Table 4 Lack of extension for patients with flexion deformity

\begin{tabular}{llll}
\hline & Pre-surgery $\left(^{\circ}\right)$ & Post-surgery $\left(^{\circ}\right)$ & Time to maximal extension $(\mathbf{m o n t h s )}$ \\
\hline Patient 1 & 12 & 0 & 1 \\
Patient 2 & 12 & 0 & 12 \\
Patient 3 & 45 & $15^{*}$ & 11 \\
\hline
\end{tabular}

*Intentionally left slight flexion deformity due to limited arc of motion secondary to condylar dysplasia

used more frequently. Several techniques can achieve this. These usually involve retrograde nailing and the use of distal blocking screws. Steiger et al. demonstrate the success of using a two-level osteotomy with retrograde nailing in 2 femurs [17]. Our technique with antegrade nailing provides a viable alternative that avoids violating the knee while still allowing accurate nail placement and precise distraction. The advantage of antegrade nailing over a retrograde approach is its ability to be used in skeletally immature patients and in children with a narrow canal [22]. This advantage is highlighted in patients with congenital deformities who might benefit from early interventions. In addition, retrograde nailing can itself increase flexion deformity and varus and valgus angulation in patients, thereby exacerbating the additional deformities present [18]. In antegrade nailing, less restriction of the knee movement can be expected [24]. Furthermore, blocking screws with nailing are commonly employed with nailing to address the distal femur deformity in conjunction with limb shortening. Iobst

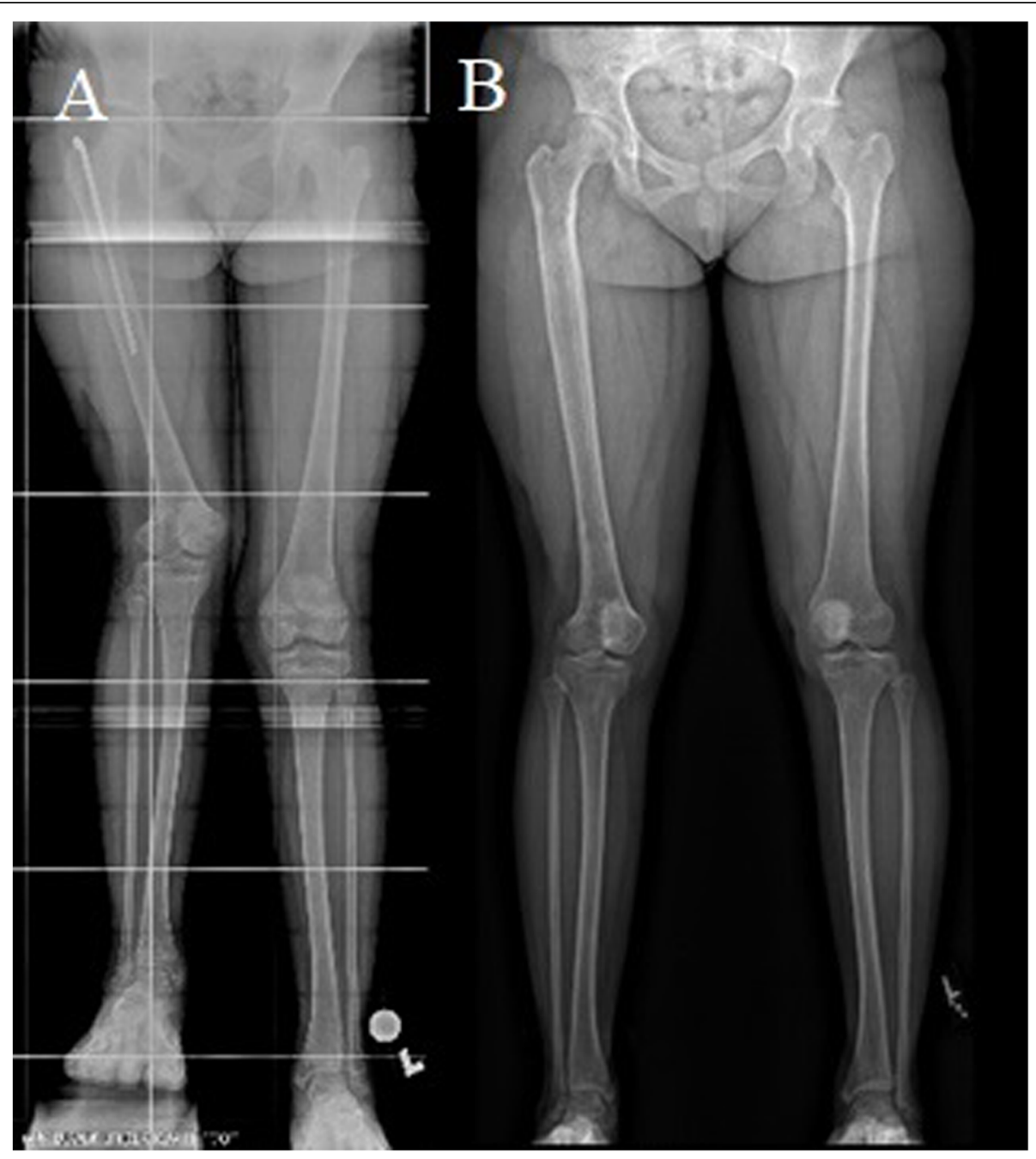

Fig. 3 Patient with an acquired leg length discrepancy and 2 prior lengthening operations for his right femur. a Right femur shortening and valgus deformity preoperatively. Patient is standing on a 6-cm block. b Significant improvement of both deformities at final follow-up 
and colleagues demonstrated the success of this approach which resulted in the correction of both the lateral distal femoral angle and the LLD in their cohort [14]. However, the use of blocking nails may be more technically challenging, whereas using a plate for stability and a trochanteric entry for nailing employs procedures more frequently performed by pediatric orthopedic deformity surgeons. The use of a nail and plate does theoretically create a stress riser between the implants, but we did not encounter any periprosthetic fractures. Future biomechanical studies could provide insight into this potential risk.

In light of the advantages of using a single procedure with an antegrade ILN and a DFO stabilized with a plate, we use this procedure to treat shortening and distal femur deformities. This technique was described by Fragomen and Fragomen who report their experience in treating three patients [18]. Satisfactory limb lengthening and distal deformity correction were achieved. The patients had knee flexion contractures in addition to short limbs. This was due to the traumatic closure of the distal femoral physis. We had similar outcomes in our cohort of congenital and acquired deformities, suggesting that this technique holds reliability in correcting limb length and distal femur deformities of different etiologies. Regarding the knee range of motion in children with flexion deformity, extension gained was between 12 and $30^{\circ}$ in our patients, similar to the $15^{\circ}$ reported by the aforementioned authors [18].

Adequate distraction and subsequent lengthening were observed in 5 patients. Despite being compliant, the remaining 2 patients had a slower lengthening rate than anticipated. This was addressed by advising them to assume a lateral decubitus position during lengthening to minimize soft tissue interference with magnet engagement, which resolved their slow progress. Nonfunctional distraction is a possible complication of using a magnetic lengthening nail, with rates of $4 \%$ being reported [8]. In the setting of slightly slow lengthening despite adequate instrumentation and use, similar conservative approaches could be tried before resorting to revision surgery.

We acknowledge the limitations of the present study. An uncommon procedure was studied, so the number of patients was small. This is common in similar articles discussing novel techniques for deformity correction, which are typically small case series $[17,18]$. Retrospective review also has the risk of suffering from inaccuracy and inconsistency. However, since the procedures were performed by the senior author at a single institution, variability in the surgical procedure, patient interviews, and documentation could be minimized. No patientreported outcomes were included. Though we attempted contacting patients to acquire functional scores, only scores from two patients were obtained. This was also limited by the absence of preoperative functional scores, so we did not include these outcomes. Nonetheless, this study still highlights a readily implementable technique for acute deformity correction as well as lengthening using a magnetic ILN, and it also shows that successful correction of the individual deformities can be achieved reliably and with minimal complications.

\section{Conclusion}

In summary, a single procedure achieving acute distal femoral angular correction and limb lengthening can be performed using a magnetic ILN and a distal femur plate, without the need for external fixation. Antegrade femur lengthening can be employed, and combining lengthening with a DFO does not appear to alter the expected result of each operation.

Future studies can help generalize our conclusion to encompass more patients and conditions, and they can have longer follow-up times into adulthood to investigate long-term results and possible complications. Moreover, patient-reported functional outcomes are pivotal to assess how patients and caregivers perceive this operation as compared to more traditional, multi-staged procedures.

\section{Abbreviations \\ DFO: Distal femoral osteotomy; ILN: Internal lengthening nail; KOOS: Knee Injury and Osteoarthritis Outcome Score; LDFA: Lateral distal femoral angle; LEFS: Lower extremity functional scale; LLD: Leg length difference; MAD: Mechanical axis deviation; MPTA: Medial proximal tibial angle; QOL: Quality of life}

\section{Acknowledgements}

Not applicable

\section{Authors' contributions}

AJ and SG have made substantial contributions to the conception and design of the work and acquisition, analysis, and interpretation of the data. AJ and SG have drafted the work and substantively revised it. Each author has approved the submitted version and has agreed both be personally accountable for the author's own contributions and to ensure that questions related to the accuracy or integrity of any part of the work, even ones in which the author was not personally involved, are appropriately investigated and resolved, and the resolution documented in the literature.

\section{Funding}

This study was supported internally by the L. Gwaltney McCollum Jr. Endowed Chair in Pediatric Orthopaedic Surgery. The funding body was not involved in the design of the study; collection, analysis, and interpretation of the data; or writing of the manuscript.

\section{Availability of data and materials \\ Not applicable}

\section{Ethics approval and consent to participate}

The University of Alabama at Birmingham Institutional Review Board approved this study with the reference number IRB-300004224. Consent was obtained from participants responding to the phone questionnaires. Consent was waived for participants who were only part of the retrospective review.

Consent for publication

Not applicable 


\section{Competing interests}

The authors declare that they have no competing interests.

\section{Author details}

${ }^{1}$ Gilbert and Rose-Marie Chagoury School of Medicine, Lebanese American University, Byblos, Lebanon. ${ }^{2}$ Department of Orthopedic Surgery, University of Alabama at Birmingham, Birmingham, AL, USA. ${ }^{3}$ Department of Pediatric Orthopaedics, ACC Suite 316, Children's Hospital of Alabama, 1600 7th Avenue South, Birmingham, AL 35233, USA.

Received: 12 October 2020 Accepted: 25 December 2020 Published online: 15 January 2021

\section{References}

1. Sabharwal S, Rozbruch SR. What's new in limb lengthening and deformity correction. J Bone Joint Surg Am. 2011;93(24):2323-32.

2. Paley D. PRECICE intramedullary limb lengthening system. Expert Rev Med Devices. 2015;12(3):231-49

3. Nlizarov GA. The tension-stress effect on the genesis and growth of tissues: part II. The influence of the rate and frequency of distraction. Clin Orthop Relat Res. 1989;(239):263-85.

4. Fragomen AT, Rozbruch SR. Retrograde magnetic internal lengthening nail for acute femoral deformity correction and limb lengthening. Expert Rev Med Devices. 2017;14(10):811-20.

5. Gordon JE, Manske MC, Lewis TR, O'Donnell JC, Schoenecker PL, Keeler KA. Femoral lengthening over a pediatric femoral nail: results and complications. J Pediatr Orthop. 2013;33(7):730-6.

6. Hamdy RC, Bernstein M, Fragomen AT, Rozbruch SR. What's new in limb lengthening and deformity correction. J Bone Joint Surg Am. 2018;100(16): 1436-42.

7. Schiedel FM, Vogt B, Tretow HL, et al. How precise is the PRECICE compared to the ISKD in intramedullary limb lengthening? Reliability and safety in 26 procedures. Acta Orthop. 2014;85(3):293-8.

8. Kirane YM, Fragomen AT, Rozbruch SR. Precision of the PRECICE internal bone lengthening nail. Clin Orthop Relat Res. 2014;472(12):3869-78.

9. Green SA, Fragomen AT, Herzenberg JE, lobst C, JJ MC, Nelson SC, Paley D, Rozbruch SR, Standard SC. A magnetically controlled lengthening nail: a prospective study of 31 individuals (the PRECICE ${ }^{\mathrm{TM}}$ intramedullary nail study). J Limb Lengthen Reconstr. 2018;4:67-75.

10. Fragomen AT, Rozbruch SR. Lengthening and deformity correction about the knee using a magnetic internal lengthening nail. SICOT J. 2017;3:25.

11. Küçükkaya M, Karakoyun Ö, Sökücü S, Soydan R. Femoral lengthening and deformity correction using the Fitbone motorized lengthening nail. J Orthop Sci. 2015;20(1):149-54.

12. Laubscher M, Mitchell C, Timms A, Goodier D, Calder P. Outcomes following femoral lengthening: an initial comparison of the Precice intramedullary lengthening nail and the LRS external fixator monorail system. Bone Joint J. 2016;98-B(10):1382-1388

13. Young C, Adcock L. PRECICE Intramedullary Limb Lengthening System: a review of clinical effectiveness. Ottawa (ON): Canadian Agency for Drugs and Technologies in Health; 2017.

14. lobst CA, Rozbruch SR, Nelson S, Fragomen A. Simultaneous acute femoral deformity correction and gradual limb lengthening using a retrograde femoral nail: technique and clinical results. J Am Acad Orthop Surg. 2018; 26(7):241-50.

15. Xu HF, Xu C, Sha J, et al. One-stage surgical treatment of simultaneous osteotomy and asymmetric lengthening on short femur with severe deformity of genu valgus. Sci Rep. 2019;9(1):8602. Published 2019 Jun 13.

16. Kocaoglu M, Eralp L, Bilen FE, Balci HI. Fixator-assisted acute femoral deformity correction and consecutive lengthening over an intramedullary nail. J Bone Joint Surg Am. 2009:91(1):152-9.

17. Steiger $\mathrm{CN}$, Lenze $\mathrm{U}$, Krieg $\mathrm{AH}$. A new technique for correction of leg length discrepancies in combination with complex axis deformities of the lower limb using a lengthening nail and a locking plate. J Child Orthop. 2018; 12(5):515-25.

18. Fragomen AT, Fragomen FR. Distal femoral flexion deformity from growth disturbance treated with a two-level osteotomy and internal lengthening nail. Strategies Trauma Limb Reconstr. 2017;12(3):159-67.

19. Mediouni M, Madiouni R, Gardner M, Vaughan N. Translational medicine: challenges and new orthopaedic vision (Mediouni-Model). Current Orthopaedic Practice. 2020;31(2):196-200.
20. Paley D. Problems, obstacles, and complications of limb lengthening by the llizarov technique. Clin Orthop Relat Res. 1990; (250):81-104.

21. Jean D, Gibbons, Chakraborti S. Comparisons of the Mann-Whitney, Student's $t$, and alternate $t$ tests for means of normal distributions. J Exp Educ. 1991;59(3):258-67.

22. Rozbruch SR, Fragomen AT. Lengthening of the femur with a remotecontrolled magnetic intramedullary nail: antegrade technique. JBJS Essent Surg Tech. 2016;6(1):e2. Published 2016 Jan 13.

23. Hammouda Al, Jauregui JJ, Gesheff MG, Standard SC, Herzenberg JE. Trochanteric entry for femoral lengthening nails in children: is it safe? J Pediatr Orthop. 2017:37(4):258-64.

24. Calder PR, McKay JE, Timms AJ, et al. Femoral lengthening using the PREC ICE intramedullary limb-lengthening system: outcome comparison following antegrade and retrograde nails. Bone Joint J. 2019;101-B(9):1168-1176.

25. Karakoyun O, Sokucu S, Erol MF, Kucukkaya M, Kabukçuoğlu YS. Use of a magnetic bone nail for lengthening of the femur and tibia. J Orthop Surg (Hong Kong). 2016;24(3):374-378.

26. Wiebking U, Liodakis E, Kenawey M, Krettek C. Limb lengthening using the PRECICE ${ }^{\text {MM }}$ nail system: complications and results. Arch Trauma Res. 2016;5(4): e36273. Published 2016 Aug 23.

\section{Publisher's Note}

Springer Nature remains neutral with regard to jurisdictional claims in published maps and institutional affiliations.
Ready to submit your research? Choose BMC and benefit from:

- fast, convenient online submission

- thorough peer review by experienced researchers in your field

- rapid publication on acceptance

- support for research data, including large and complex data types

- gold Open Access which fosters wider collaboration and increased citations

- maximum visibility for your research: over $100 \mathrm{M}$ website views per year

At BMC, research is always in progress.

Learn more biomedcentral.com/submissions 